Journal of Experimental and Clinical Medicine https://dergipark.org.tr/omujecm

Review Article

$\mathrm{J}$ Exp Clin Med

2021; 38(4): 645-648

doi: 10.52142 /omujecm.38.4.43

\title{
NSAIDs medication for headache as the presenting symptom with migraine and COVID-19
}

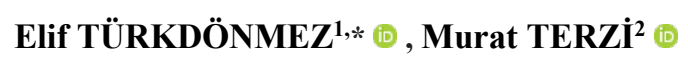

${ }^{1}$ Department of Physiology, Faculty of Medicine, University of Ondokuz Mayıs University, Samsun, Turkey

${ }^{2}$ Department of Neurology, Faculty of Medicine, University of Ondokuz Mayıs University, Samsun, Turkey

\begin{abstract}
Received: 10.04 .2021
Accepted/Published Online: 23.04.2021

$\bullet$

Final Version: 30.08.2021

\section{Abstract}

Headache is one of the most prevalent disorders of the nervous system. Headache is also the most common symptom of a variety of diseases, including migraine, COVID-19. International Classification of Headache Disorders (ICHD) lists over a thousand different types of headaches. Migraine is a widely known type of primary headache. Much research supports that the enhancement in migraine intensity related to chronic migraine such as neurogenic neuroinflammation, possibly leading to increased cytokine expression via activation of protein kinases in neurons and glial cells of the trigeminovascular system like some of the other headache diseases. No currently drug class available, either specific (triptans, ergots) or non-specific (opioids, paracetamol, NSAIDs), is effective in all types of headaches, in all patients and all attacks of the same patient. However, non-steroidal anti-inflammatory drugs (NSAIDs) minimize prostaglandin synthesis by blocking cyclooxygenase, which is included in the pathophysiology of migraine headaches. We searched the employed source was The Journal of Headache and Pain database by using NSAIDs with Headache, Migraine, and COVID-19 keywords. The search was performed from April 2021 and included 2017-2018-20192020-2021 (last five years) the studies and reviews from the Journal of Headache and Face Pain Sites. Additionally, we noted the published or on-going studies, eight of these, about NSAIDs information contain searches that exist in the $12^{\text {th }}$ European Headache Federation Congress (jointly with $32^{\text {nd }}$ National Congress of the Italian Society) Study of Headaches' book. Also, we included relationship migraine with COVID-19 studies to highlight the connection between the headache, which is one of the most common symptoms of both migraine and COVID-19, and the importance of managing migraine pain with NSAIDs during corona processing.
\end{abstract}

Keywords: headache, migraine, neuroinflammation, non-steroid anti-inflammatory drugs (NSAIDS)

\section{Introduction}

Headache disorders remain one of the prevalent medical problems, most people experience them at a stage in their life regardless of age, gender, and race. Additionally, while COVID-19 viruses embracing the world are mainly a respiratory illness characterized by symptoms of cough, fever, and respiratory distress; headache is one of the most common neurological symptoms in COVID-19 (1). The International Classification of Headache Disorders (ICHD) explained more than 150 different versions of headaches. However, they fall into two subtitles, primary headaches, and secondary headaches. Primary headaches are headaches that are standalone disorders caused by independent pathomechanism and not by other disorders whereas secondary headaches are underlying other causes such as severe illness, high blood pressure (2). As migraines, tension headaches, cluster headaches, exertional headaches, and hypnic headaches are fallen under primary headaches while medication-overuse headaches, airplane headaches, and pregnant-related headaches, post-traumatic headaches are included by secondary headaches. Identification of the patient subgroups with different sensitization scales and clinical characteristics can help identify at-risk groups and help to develop better therapeutic strategies/tactical approaches (3).
A systematic searching about headache from 495 papers published in 2018, analyzed that common analgesics such as acetaminophen/paracetamol or metamizole, non-steroidal anti-inflammatory drugs (NSAIDs), triptans, anti-emetics (if employed for pain relief), opioids, ergot derivatives, caffeine, magnesium, oxygen, devices that could be easily procured by patients at home for headaches. Moreover, the result of the search showed that NSAIDs are the most common participants in this many studies like the research (4-7).

No currently drug class available, either specific (triptans, ergots) or non-specific (opioids, paracetamol, NSAIDs), is effective in all types of headaches, in all patients and also in all attacks of the same patient (8-12). Besides, a healing process of any headaches with any drug can be affected by many reasons as well as for the formation of pain, the pregnant term, caffeine, cannabis use, over-weight obesity, drug-drug interaction, types of administration (topical or injection or different form of the drugs such as nimesulide gel form, etc.) $(6,13-18)$. And a correctly characterized headache is of great importance to take precautions against these reasons. For example, if a migraine diagnosed patient puts down the daily coffee, pay attention to what he/she eats; he/she can make better his/her life with migraine. NSAIDs in the treatment of migraine, COVID-19, and COVID-19 
migraine patients Migraine is the primary type of headache characterized by persistent headaches that are moderate to severe. Migraine has been proclaimed to be the third prevalent disorder and the second cause of disability by WHO (21). The exact pathophysiology of migraine is still not clear. However, some theories can be explaining how migraine is produced. The vascular theory is vascular disturbances (vasodilatation-vasoconstriction) causing migraine symptoms associated with inflammation and the serotonin system; the neural theory is hyperexcitability in the form of cortical spreading depression leads to migraine through a cascade involving inflammation and sympathetic nervous system whereas the alternative theory that may overlap with a mechanism which activates neural inflammation and it leads to migraine pain (22). Even if the evidence of a direct role of COX-2 on the face and headache pain is still controversial and inhibited with cyclooxygenase inhibition by NSAIDs, which avoids the conversion of arachidonic acid into the inactive prostaglandin precursor, prostaglandin $\mathrm{H}_{2}\left(\mathrm{PGH}_{2}\right)$, is a basis of the acute migraine attack, thus implicating prostaglandins in migraine pain $(20,23-25)$. But, NSAIDs are not one way to treatment for migraine diseases (26). For example, if headaches are mild to moderate in intensity, generally, it is favorable to initiate with a NSAID (acetylsalicylic acid used in medicines like Aspirin, diclofenac, ibuprofen) or acetaminophen (paracetamol) to be started as a first. This is the most appropriate strategy that has been found unless the patient has already tried over-thecounter medicines. If this proves ineffective, the triptan option or combinations of the drugs can be attempted/followed the next (5). Many pieces of the research mention that the drugs' effectiveness, differences from NSAIDs, and the effect of their combination treatment with NSAIDs on migraine or other headaches $(7,11,14,16,19$, 27-34). But the usage of the drugs has to be controlled by doctors or pharmacists. Because mindfulness medication is dangerous and might cause some risks such as overuse headache or GI comorbidity like side effects with or without drugs used for other diseases $(20,35)$. For example, analysis shows a correlation with sociodemographic variables and indices of symptom severity by professional healthcare providers (HCPs). And the analyses show that medicationoveruse headache consulted most $(87.0 \%)$, followed by those with migraine $(67.2 \%)$ and those with tension-type headache (48.6\%; p <0.001) (13, 27, 34, 36-40). Moreover, several reports emerged on March 14, 2020, raising fears that NSAIDs, e.g., ibuprofen) may worsen symptoms of COVID19. A substantial body of evidence suggests that NSAIDs can alter the course of bacterial pneumonia, resulting in more invasive disease and complications, as well as higher rates of hospitalization and intensive care unit admission (41-43). There is reasonable evidence for an association between NSAIDs and respiratory and cardiovascular side effects in a variety of settings, but no evidence directly related to people with COVID-19 (44). However, before administering any drug, physicians can thoroughly test for COVID-19 symptoms and notify patients. NSAIDs should be stayed away from medication (45).

In addition to the current pharmacological treatment with the drugs, some point of pain area is important to take as a target with drugs or physical techniques. Such REN technique and cervical myofascial point targeting with drugs etc. exist (20). Moreover, preventive therapies such as Yoga, relaxation therapies might shorten the treatment period $(11,46)$.

In this study, we reached the following results, which we conducted that much researches about effectiveness and cost were the main criteria to choose drugs, conclude that national stakeholders in cooperation with scientific organizations should be implicated in continuous clinical practice and education concerning appropriate counseling processes and that, as with any disease, its interaction with drugs used for other diseases should be considered $(32,36)$.

\section{Conclusion}

Headaches are one of the most common health issues, affecting almost everyone at some stage in their lives, regardless of age, gender, or race. Migraine is a much more severe form of headache and also a very prevalent neurological disease that affects people all over the world. It is also the most common symptom for the COVID-19 epidemic that affects the world. NSAIDs are most effective on migraine or many other headaches. However, in the treatment of both migraine disease with COVID-19 and headaches due to COVID -19, regardless of this observation, we agree that paracetamol (acetaminophen) should be used first in headache management before starting to NSAIDs because of paracetamol's greater tolerability $(47,48)$. As the result, developing better therapeutic strategies is mostly related to an accurate diagnosis of headache types and also to its interaction with drugs used for other diseases that occur at the same time with migraine such as COVID-19 (5). And also, price, effectiveness, and safety are the main things to choose medication by the patients (49-51).

\section{Conflict of interest}

The authors have no conflict of interest to declare. The authors alone are responsible for the content and writing of this review.

\section{Acknowledgments}

None.

\section{References}

1. Edvinsson L, Haanes KA, Warfvinge K. Does inflammation have a role in migraine? Nat Rev Neurol. 2019;15(8):483-90.

2. Benhaddi H, Fitzgerald T, SophieMcCabe RZ. Correction to: 12th European Headache Federation Congress jointly with 32nd National Congress of the Italian Society for the Study of Headaches. J Headache Pain. 2018; 19:119.

3. Bolay H, Gül A, Baykan B. COVID-19 is a Real Headache! Headache. 2020 Jul;60(7):1415-1421. doi: 10.1111/head.13856. Epub 2020 May 27. PMID: 32412101; 


\section{PMCID: PMC7272895.}

4. Headache Classification Committee of the International Headache Society (IHS). The International Classification of Headache Disorders, 3rd edition (beta version). Cephalalgia. 2013 Jul;33(9):629-808. doi: 10.1177/0333102413485658. PMID: 23771276.

5. Ong JJY, De Felice M. Migraine treatment: current acute medications and their potential mechanisms of action. Neurotherapeutics. 2018;15(2):274-90.

6. Hjalte F, Olofsson S, Persson U, Linde M. Burden and costs of migraine in a Swedish defined patient population-a questionnaire-based study. J Headache Pain. 2019;20(1):1-9.

7. García-Azorin D, Yamani N, Messina L, Peeters I, Ferrili M, Ovchinnikov D, et al. A PRISMA-compliant systematic review of the endpoints employed to evaluate symptomatic treatments for primary headaches. J Headache Pain. 2018;19(1):1-11.

8. Galioto R, O'Leary KC, Thomas JG, Demos K, Lipton RB, Gunstad J, et al. Lower inhibitory control interacts with greater pain catastrophizing to predict greater pain intensity in women with migraine and overweight/obesity. J Headache Pain. 2017;18(1):1-8

9. Negro A, Spuntarelli V, Sciattella P, Martelletti P. Rapid referral for headache management from emergency department to headache centre: four years data. J Headache Pain. 2020;21(1):25.

10. Vollesen AL, Benemei S, Cortese F, Labastida-Ramírez A, Marchese F, Pellesi L, et al. Migraine and cluster headache-the common link. J Headache Pain. 2018;19(1):1-15.

11. Piccinni C, Cevoli S, Ronconi G, Dondi L, Calabria S, Pedrini A, et al. A real-world study on unmet medical needs in triptantreated migraine: prevalence, preventive therapies and triptan use modification from a large Italian population along two years. J Headache Pain. 2019;20(1):1-9.

12. Lupi C, Benemei S, Guerzoni S, Pellesi L, Negro A. Pharmacokinetics and pharmacodynamics of new acute treatments for migraine. Expert Opin Drug Metab Toxicol. 2019 Mar;15(3):189-198. doi: 10.1080/17425255.2019.1578749. Epub 2019 Feb 12. PMID: 30714429 .

13. Do TP, Heldarskard GF, Kolding LT, Hvedstrup J, Schytz HW. Myofascial trigger points in migraine and tension-type headache. J Headache Pain. 2018;19(1):1-17.

14. Chen W-T, Chou K-H, Lee P-L, Hsiao F-J, Niddam DM, Lai $\mathrm{K}-\mathrm{L}$, et al. Comparison of gray matter volume between migraine and "strict-criteria" tension-type headache. J Headache Pain. 2018;19(1):1-11.

15. Pomes LM, Guglielmetti M, Bertamino E, Simmaco M, Borro M, Martelletti P. Optimising migraine treatment: from drugdrug interactions to personalized medicine. J Headache Pain. 2019;20(1):1-12.

16. Negro A, Delaruelle $Z$, Ivanova $T$, Khan $S$, Ornello R, Raffaelli B, et al. Headache and pregnancy: a systematic review. J Headache Pain. 2017;18(1):1-20.

17. Lipton RB, Diener H-C, Robbins MS, Garas SY, Patel K. Caffeine in the management of patients with headache. J Headache Pain. 2017;18(1):1-11.

18. Haanes KA, Labastida-Ramírez A, Chan KY, de Vries R, Shook B, Jackson P, et al. Characterization of the trigeminovascular actions of several adenosine A $2 \mathrm{~A}$ receptor antagonists in an in vivo rat model of migraine. J Headache Pain. 2018;19(1):1-10.
19. Baron EP, Lucas P, Eades J, Hogue O. Patterns of medicinal cannabis use, strain analysis, and substitution effect among patients with migraine, headache, arthritis, and chronic pain in a medicinal cannabis cohort. J Headache Pain. 2018;19(1):128.

20. Affaitati G, Costantini R, Tana C, Lapenna D, Schiavone C, Cipollone $\mathrm{F}$, et al. Effects of topical vs injection treatment of cervical myofascial trigger points on headache symptoms in migraine patients: a retrospective analysis. J Headache Pain. 2018;19(1):1-10.

21. Stovner LJ, Nichols E, Steiner TJ, Abd-Allah F, Abdelalim A, Al-Raddadi RM, et al. Global, regional, and national burden of migraine and tension-type headache, 1990-2016: a systematic analysis for the Global Burden of Disease Study 2016. Lancet Neurol. 2018 Nov;17(11):954-976. doi: 10.1016/S14744422(18)30322-3. PMID: 30353868; PMCID: PMC6191530.

22. Reddy DS. The pathophysiological and pharmacological basis of current drug treatment of migraine headache. Expert Rev Clin Pharmacol. 2013; 6(3):271-88. doi: 10.1586/ecp.13.14. PMID: 23656340.

23. Barbanti P, Grazzi L, Egeo G. Pharmacotherapy for acute migraines in children and adolescents. Expert Opin Pharmacother. 2019 Mar;20(4):455-463. doi: 10.1080/14656566.2018.1552941. Epub 2018 Dec 7. PMID: 30526161 .

24. Yu S, Zhang $\mathrm{Y}$, Yao $\mathrm{Y}$, Cao H. Migraine treatment and healthcare costs: retrospective analysis of the China Health Insurance Research Association (CHIRA) database. J Headache Pain. 2020;21(1):53.

25. Roessler T, Zschocke J, Roehrig A, Friedrichs M, Friedel H, Katsarava Z. Administrative prevalence and incidence, characteristics and prescription patterns of patients with migraine in Germany: a retrospective claims data analysis. J Headache Pain. 2020;21(1):85.

26. Landini L, Janal MN, Simone LP, Pierangelo G, Romina N. Migraine-provoking substances evoke periorbital allodynia in mice. J Headache Pain. 2019;20(1).

27. Viganò A, Torrieri MC, Toscano M, Puledda F, Petolicchio B, D'Elia TS, et al. Neurophysiological correlates of clinical improvement after greater occipital nerve (GON) block in chronic migraine: relevance for chronic migraine pathophysiology. J Headache Pain. 2018;19(1):1-9.

28. Vandenbussche N, Laterza D, Lisicki M, Lloyd J, Lupi C, Tischler $\mathrm{H}$, et al. Medication-overuse headache: a widely recognized entity amidst ongoing debate. J Headache Pain. 2018;19(1):1-14

29. van Hoogstraten WS, MaassenVanDenBrink A. The need for new acutely acting antimigraine drugs: moving safely outside acute medication overuse. J Headache Pain. 2019;20(1):1-7.

30. Ueda K, Ye W, Lombard L, Kuga A, Kim Y, Cotton S, et al. Real-world treatment patterns and patient-reported outcomes in episodic and chronic migraine in Japan: analysis of data from the Adelphi migraine disease specific programme. J Headache Pain. 2019;20(1):1-11.

31. Petrovski BÉ, Vetvik KG, Lundqvist C, Eberhard-Gran M. Characteristics of menstrual versus non-menstrual migraine during pregnancy: a longitudinal population-based study. J Headache Pain. 2018;19(1): 1-9.

32. Netere AK, Erku DA, Sendekie AK, Gebreyohannes EA, Muluneh NY, Belachew SA. Assessment of community pharmacy professionals' knowledge and counseling skills achievement towards headache management: a cross-sectional 
and simulated-client based mixed study. J Headache Pain. 2018;19(1):1-9.

33. Loo LS, Ailani J, Schim J, Baygani S, Hundemer H-P, Port M, et al. Efficacy and safety of lasmiditan in patients using concomitant migraine preventive medications: findings from SAMURAI and SPARTAN, two randomized phase 3 trials. J Headache Pain. 2019;20(1):1-11.

34. Grazzi L, Sansone E, Raggi A, D'Amico D, De Giorgio A, Leonardi $\mathrm{M}$, et al. Mindfulness and pharmacological prophylaxis after withdrawal from medication overuse in patients with Chronic Migraine: an effectiveness trial with a one-year follow-up. J Headache Pain. 2017;18(1):1-12.

35. Buse DC, Reed ML, Fanning KM, Bostic R, Dodick DW, Schwedt TJ, et al. Comorbid and co-occurring conditions in migraine and associated risk of increasing headache pain intensity and headache frequency: results of the migraine in America symptoms and treatment (MAST) study. J Headache Pain. 2020;21(1):23.

36. Tassorelli $\mathrm{C}$, Tramontano $\mathrm{M}$, Berlangieri $\mathrm{M}$, Schweiger $\mathrm{V}$, D'ippolito M, Palmerini $\mathrm{V}$, et al. Assessing and treating primary headaches and cranio-facial pain in patients undergoing rehabilitation for neurological diseases. J Headache Pain. 2017;18(1):1-18.

37. Schwedt TJ, Alam A, Reed ML, Fanning KM, Munjal S, Buse DC, et al. Factors associated with acute medication overuse in people with migraine: results from the 2017 migraine in America symptoms and treatment (MAST) study. J Headache Pain. 2018;19(1):1-9.

38. Manandhar K, Risal A, Linde M, Steiner TJ. Health-care utilization for headache disorders in Nepal: a population-based door-to-door survey. J Headache Pain. 2018;19(1):1-9.

39. Fischer MA, Jan A. Medication-overuse Headache. 2020 Jun 30. In: StatPearls [Internet]. Treasure Island (FL): StatPearls Publishing; 2021 Jan-. PMID: 30844177.

40. Baker VB, Eliasen KM, Hack NK. Lifestyle modifications as therapy for medication refractory post-traumatic headache (PTHA) in the military population of Okinawa. J Headache Pain. 2018;19(1):1-8.

41. Voiriot G, Dury S, Parrot A, Mayaud C, Fartoukh M. Nonsteroidal antiinflammatory drugs may affect the presentation and course of community-acquired pneumonia. Chest. 2011 Feb;139(2):387-394. doi: 10.1378/chest.09-3102.
Epub 2010 Aug 19. PMID: 20724739.

42. Chowdhury D, Datta D. Managing Migraine in the Times of COVID-19 Pandemic. Ann Indian Acad Neurol. 2020 Apr;23(Suppl 1): S33-S39. doi: 10.4103/aian.AIAN_296_20. Epub 2020 Apr 20. PMID: 32419752; PMCID: PMC7213033.

43. Bobker SM, Robbins MS. COVID-19 and Headache: A Primer for Trainees. Headache. 2020 Sep;60(8):1806-1811. doi: 10.1111/head.13884. Epub 2020 Jun 19. PMID: 32521039; PMCID: PMC7300928.

44. Little P. Non-steroidal anti-inflammatory drugs and covid-19. BMJ. 2020 Mar 27;368:m1185. doi: 10.1136/bmj.m1185. PMID: 32220865.

45. Pradère B, Ploussard G, Catto JW, Rouprêt M, Misrai V. The Use of Nonsteroidal Anti-inflammatory Drugs in Urological Practice in the COVID-19 Era: Is "Safe Better than Sorry"? Eur Urol. 2020 Aug;78(2):134-135. doi: 10.1016/j.eururo.2020.03.033. Epub 2020 Apr 10. PMID: 32284245 ; PMCID: PMC7151479.

46. Rapoport AM, Bonner JH, Lin T, Harris D, Gruper Y, Ironi A, et al. Remote electrical neuromodulation (REN) in the acute treatment of migraine: a comparison with usual care and acute migraine medications. J Headache Pain. 2019;20(1):1-7.

47. MaassenVanDenBrink A, de Vries T, Danser AHJ. Headache medication and the COVID-19 pandemic. J Headache Pain. 2020;21(1):38.

48. Antoinette M, Jan DA. Headache medication and the COVID19 pandemic. J Headache Pain. 2020;21(1).

49. Netere AK, Erku DA, Sendekie AK, Gebreyohannes EA, Muluneh NY, Belachew SA. Assessment of community pharmacy professionals' knowledge and counseling skills achievement towards headache management: a cross-sectional and simulated-client based mixed study. J Headache Pain. 2018;19(1):96.

50. Hjalte F, Olofsson S, Persson U, Linde M. Burden and costs of migraine in a Swedish defined patient population - a questionnaire-based study. J Headache Pain. 2019;20(1):65.

51. Diener HC, Antonaci F, Braschinsky M, Evers S, Jensen R, Lainez M, et al. European Academy of Neurology guideline on the management of medication-overuse headache. Eur J Neurol. 2020 Jul;27(7):1102-1116. doi: 10.1111/ene.14268. Epub 2020 May 19. PMID: 32430926. 